\title{
Cost-Benefit Model and Benefit Distribution Mode of Critical-Peak Pricing
}

\author{
Bin Yang ${ }^{1}$, Wenjun Ruan ${ }^{1 \mathrm{a}}$, Chu Chen ${ }^{1}$, Yusun $\mathrm{Luo}^{2}$, Jiaqi $\mathrm{Hu}^{2}$ \\ ${ }^{1}$ State Grid Jiangsu Province Electric Power Company, Nanjing, 210000, China \\ ${ }^{2}$ Beijing Huiheshi Technology Co. Ltd, Beijing, 100000, China \\ aemail: zj_rwj@163.com
}

Keywords: Critical-Peak Pricing; Cost-Benefit; Benefit Distribution; Demand Side Management

\begin{abstract}
In this paper, the cost and benefit of different participants in critical-peak pricing project are analyzed. Cost-benefit models of power generation company, power grid company, power consumers and government departments are established. Furthermore, benefit distribution modes of different stages in critical-peaking pricing project are discussed. The results of case study demonstrate the feasibility and effectiveness of the benefit distribution modes.
\end{abstract}

\section{Introduction}

As the evolution of power industry, demand side management (DSM) is getting more and more attention as an effective approach of load management. DSM can be regarded as plans and approaches for achieving expected load curve by influencing customer's power consumption[1][2]. The research achievements demonstrate that critical-peak pricing could be an effective approach in DSM. It leads customer to adopt reasonable power consumption structure by shaping the electricity price, so that the load demand at peak period can be reduced. Therefore, higher load ratio and equipment utilization is achieved. Meanwhile, the power system operates more reliably and economically, which results in more energy saving and optimal resource dispatch. For effective implementation of critical-peak pricing(CPP), it is important and necessary to guarantee that margins obtained by all participants remain the same or higher. Thus, effective analysis of cost and benefit of CPP scheme can be treated as basis of successful implementation of DSM approach and important reference to attract active participation.

Currently, progress and achievements are made in the analysis of cost and benefit of DSM approaches. In literature[3], evaluation indicator system and corresponding calculation model are derived. Literature[4][5] emphasizes the necessity of fair benefit distribution to successful implementation of DSM approach. In literature[6][7], cost and benefit of three participants of DSM, namely the power consumer, power generation company and government departments are analyzed. Also, the optimal benefit model and computer simulation model are derived.

With consideration of the latest situation in power industry, this paper analyzes the cost-benefit model of all the participants in CPP project and gives a case study to verify the effectiveness of the model.

\section{Cost-Benefit Model of Critical-Peak Pricing}

\section{Cost-Benefit Model of Power Grid Company.}

As the executor of CPP, the power grid company has to guarantee certain margin during the process of implementation. The cost of CPP implementation consists of relevant equipment investment, project management and income loss of electricity selling. The benefit for power grid company consists of capacity dispensable cost and purchasing dispensable cost. Normally, the capacity dispensable cost can be derived by calculation of the reduced investment for distribution stations, transformers, transmission lines, and other equipments. As for the purchasing dispensable cost, saved expenses by peak cutting and valley filling are usually indicated.

Therefore, the cost-benefit model of power grid company can be derived as below, 


$$
\left\{\begin{array}{c}
C_{g}=\sum_{i=1}^{n} C_{g i}=\sum_{i=1}^{n} K_{i}\left(E_{i}+M_{i}+R_{i}\right) \\
B_{g}=\sum_{i=1}^{n} B_{g i}=\sum_{i=1}^{n} K_{i}\left(\Delta T_{i} P_{i}+Q_{i}\right)
\end{array}\right.
$$

In equation(1), $C_{g}$ and $B_{g}$ are total cost and total benefit of power grid company respectively when the CPP is implemented. $C_{g i}$ and $B_{g i}$ are the cost and benefit of the ith year. $E_{i}$ and $M_{i}$ are the equipment investment cost and project management cost of the ith year. $\Delta \mathrm{T}_{\mathrm{i}}$ is the saved expenses realized by peak cutting and valley filling. $P_{i}$ is the capacity dispensable cost of the ith year and $n$ is the number of years of CPP implementation. $K_{i}$ is the price of the ith year. $R_{i}$ and $Q_{i}$ are the income loss of electricity selling and purchasing dispensable cost, respectively.

\section{Cost-Benefit Model of Power Consumers.}

The benefit of power consumers related to CPP is the reduced payment and the cost consists of equipment investment and project management. With further consideration of project management cost, operation and maintenance payment are included. Hence, the cost-benefit model of power consumers can be summarized as following,

$$
\left\{\begin{array}{c}
C_{c}=\sum_{i=1}^{n} C_{c i}=\sum_{i=1}^{n} K_{i}\left(F_{i}+N_{i}\right) \\
B_{c}=\sum_{i=1}^{n} B_{c i}=\sum_{i=1}^{n} K_{i} R_{i}
\end{array}\right.
$$

In equation(2), $C_{c}$ and $B_{c}$ are total cost and total benefit of power consumers when the CPP is implemented. $C_{c i}$ and $B_{c i}$ are the cost and benefit of the ith year. $F_{i}$ and $N_{i}$ are the equipment investment cost and project management cost of the ith year. It is noted that $E_{i}$ and $F_{i}$ are the equipment investment of power grid company and power consumers, respectively. The sum of $E_{i}$ and $F_{i}$ is the total equipment investment for implementation of CPP.

\section{Cost-Benefit Model of Power Generation Company.}

Similar to the power grid company, the benefit for power generation company consists of capacity dispensable cost and purchasing dispensable cost when implementing CPP. The capacity dispensable cost can be derived by calculation of the reduced investment for power generators. As for the purchasing dispensable cost, saved expenses of reduced fuel and environmental pollution compensation. The cost of power generation company consists of on-grid electricity expense loss and relevant equipment investment. Due to far less equipment investment related to CPP for power generation company comparing to power grid company, this part can be reasonably ignored. So, the cost-benefit model of power generation company can be concluded as below,

$$
\left\{\begin{array}{c}
C_{p}=\sum_{i=1}^{n} C_{p i}=\sum_{i=1}^{n} K_{i} H_{i} \\
B_{p}=\sum_{i=1}^{n} B_{p i}=\sum_{i=1}^{n} K_{i} \Delta T_{i}\left(J_{i}+L_{i}\right)
\end{array}\right.
$$

In equation(3), $C_{p}$ and $B_{p}$ are total cost and total benefit of power generation company when the CPP is implemented. $\mathrm{Cp}_{\mathrm{i}}$ and $\mathrm{Bp}_{\mathrm{i}}$ are the cost and benefit of the ith year. $\mathrm{J}_{\mathrm{i}}$ and $\mathrm{L}_{\mathrm{i}}$ are the individual share of the capacity dispensable cost and purchasing dispensable cost of the ith year.

\section{Cost-Benefit Model of Government Department.}

For the analysis of cost-benefit model of government department, it is reasonable to comprehensively investigate and evaluate the cost expense and social benefit after implementation of CPP. However, due to the interaction of cost and benefit of the aforementioned three participants, it is usually difficult to calculate in quantity. In this paper, full resources analysis is employed to replace cost-benefit analysis of the whole society.

To the full resources, the total cost indicates all the expense when implementing CPP. Other expenses such as saved payment of customers, purchasing dispensable cost are ignored, because they belong to internal financial transfer of the society. Hence, the cost-benefit model of the 
government department can be summarized as following,

$$
\left\{\begin{array}{c}
C_{s}=\sum_{i=1}^{n} C_{s i}=\sum_{i=1}^{n} K_{i}\left(E_{i}+M_{i}+F_{i}+N_{i}\right) \\
B_{s}=\sum_{i=1}^{n} B_{s i}=\sum_{i=1}^{n} K_{i} \Delta T_{i}\left(P_{i}+J_{i}+L_{i}\right)
\end{array}\right.
$$

In equation(4), $C_{s}$ and $B_{s}$ are total cost and total benefit of the society when the CPP is implemented. $\mathrm{C}_{\mathrm{si}}$ and $\mathrm{B}_{\mathrm{s}} \mathrm{i}$ are the cost and benefit of the ith year.

\section{Benefit Distribution Mode of Critical-Peak Pricing}

\section{Initial Stage.}

At the initial stage of CPP, the project is drived by government, and government ought to provide financial support for the project. With the investment of government, the benefit flows to users and certain level environmental effects are generated. The income of the power grid company might drop, which can be compensated by initiative policy coming from government. The block diagram of the benefit distribution mode at the initial stage can be described as Fig.1,

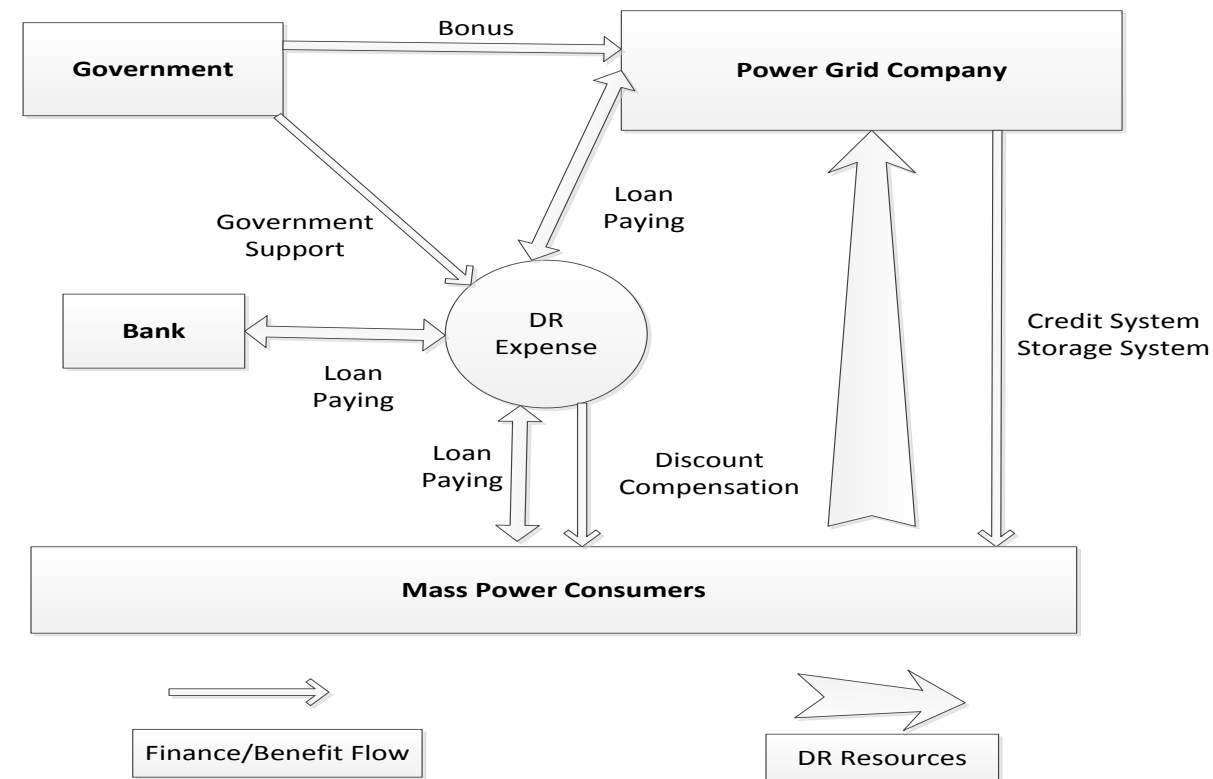

Fig.1. Benefit distribution mode of CPP at initial stage

\section{Developing Stage.}

At the developing stage, the details of the guiding instructions are improved and the coverage area of the incentive policy becomes wider. The long-term reliable operation of CPP is supported by relevant evaluation and monitoring system. After active participation of the aforementioned individuals, the benefit for the consumers gets higher and the power grid company is propelled by the incentive policy. The third party such as energy-serving companies are also involved in the project. Due to the stronger financial support and higher efficiency of the project execution, the benefit of the CPP project gets higher. By redistributing the benefit through incentive mechanism, excellent benefit sharing is achieved. The block diagram of the benefit distribution mode at the developing stage can be described as Fig.2, 


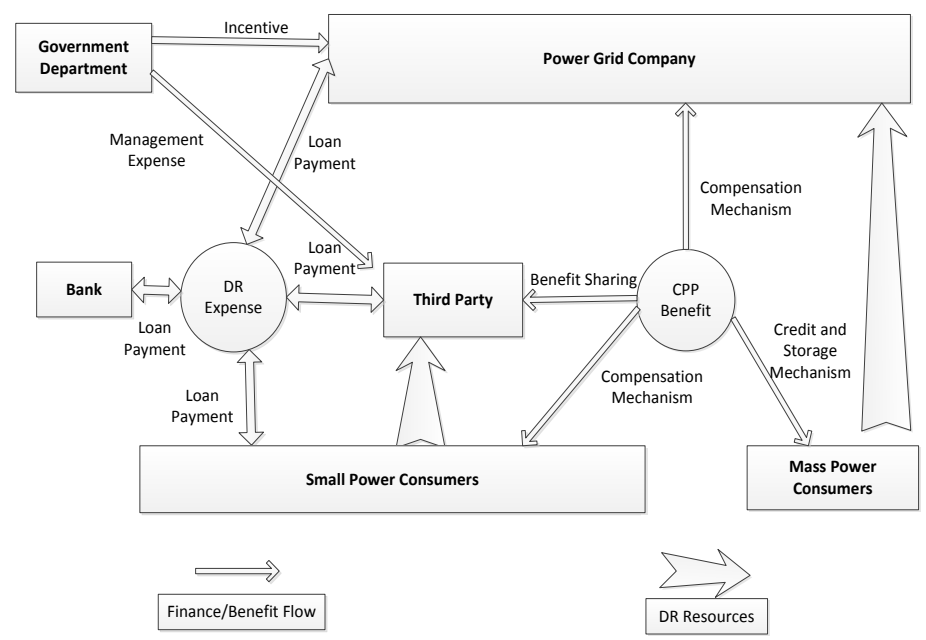

Fig.2. Benefit distribution mode of CPP at developing stage

\section{Steady Stage.}

When the CPP project comes to the steady stage, strong connections among power grid company, power consumer and the third party. The benefit gets redistribution by employing reasonable incentive mechanism. Meanwhile, the effect of monitoring and execution is strengthened under the supervision of government. Comparing to the developing stage, the participants don't need discount compensation to excite the CPP project. The policy and regulation of CPP implementation are fully developed, while the effects of CPP are well understood by all the participants. The block diagram of the benefit distribution mode at the steady stage can be described as Fig.3,

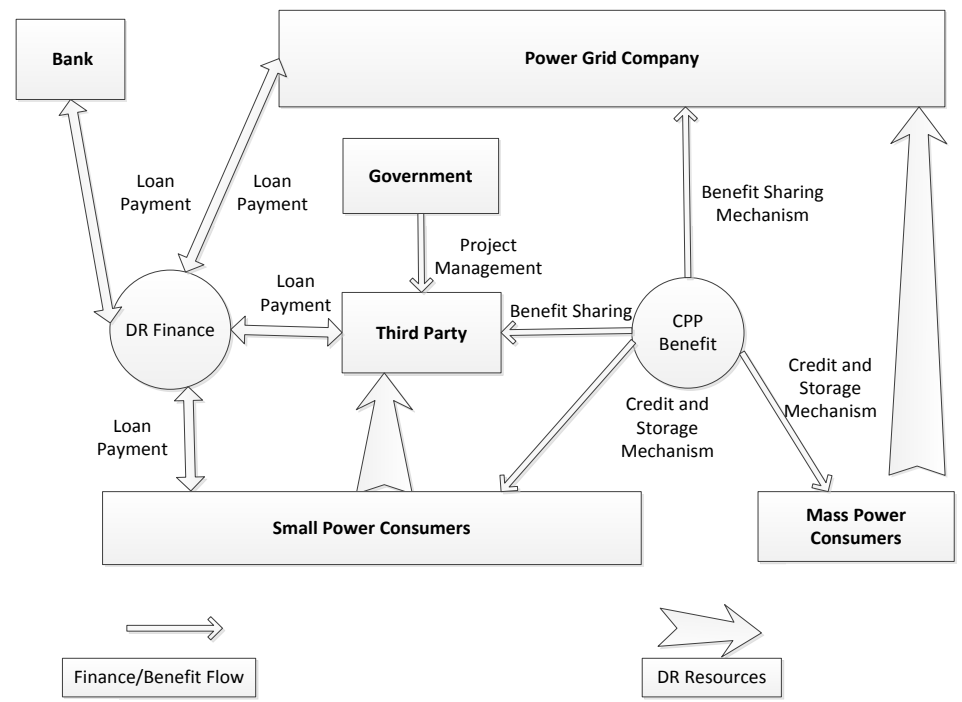

Fig.3. Benefit distribution mode of CPP at steady stage

\section{Case Study}

\section{Scenario Design.}

A. 100 attendees of the CPP project in the study area and the response capacity at critical-peak day is $1 \mathrm{MWh}$.

B. Credit ranking of the attendees is listed as following.

Table.1 Credit Ranking and Response Ratio

\begin{tabular}{|c|c|c|}
\hline Credit Level & Response ratio & Practical response ratio \\
\hline High & $80 \% \sim$ & $60 \% \sim$ \\
\hline Medium & $60 \% \sim 80 \%$ & $40 \% \sim 60 \%$ \\
\hline Low & $50 \% \sim 60 \%$ & $30 \% \sim 40 \%$ \\
\hline None & $\sim 50 \%$ & $\sim 50 \%$ \\
\hline
\end{tabular}


C. CPP is $1.9104 \mathrm{RMB}$ per $\mathrm{kWh}$, price of the other time intervals is $0.8174 \mathrm{RMB}$ per $\mathrm{kWh}$.

\section{Benefit Analysis.}

With the assumption of 10 DR plans are initiated by power grid company during summer time, and 10MWh reduction for each time, user A responded 7 time, exchanged twice and lost once. Then, the response ratio of user A is $90 \%$ and practical response ratio is $70 \%$. The credit level of user A is high. Due to the response times, user A scored 7000 points and another 3000 points for the exchange as well as 2000 points reduction for no response. Assume 1 point equivalent to $1 \mathrm{kWh}$ for peak avoidable capacity and 1.5 point equivalent to $1 \mathrm{kWh}$ for exchanged electricity, the total quantity of electricity from points exchanging is $667 \mathrm{kWh}$.

The saved expenses of user A can be listed as following,

A. 7 peak period expenses:

$1.9104 * 7 * 1000=13373 \mathrm{RMB}$

B. Points exchange at 2 peak period:

$1.9104 * 2 * 1000=3821 \mathrm{RMB}$

C. Rest points exchange:

$0.8174 * 667=545 \mathrm{RMB}$

The total expense saved by user A is 17739RMB.

\section{Conclusion}

The benefit of CPP project can be distributed fairly among all the participants by employing reasonable and effective analysis model. The case study demonstrates the feasibility and effectiveness of the discussed cost-benefit model and benefit distribution mode of CPP project.

\section{Acknowledgement}

The authors would like to give their gratitude to the support of project "Research and application on key dynamic optimization technology of Public buildings' smart power mode”, which is a 2015 technology project from China state grid.

\section{References}

[1] D. Kirschen. Demand side view of electricity markets[J]. IEEE Transactions on Power Systems, 2003, 18(2): 520-527.

[2] P. Palensky, D. Dietrich. Demand side management: Demand response, intelligent energy systems, and smart loads[J]. IEEE Transactions on Industrial Informatics 2011, 7(3): 381-388.

[3] J.Liu. Evaluation index and model of demand side management[J]. North China Electric Power, 2003, 7: 10-11.

[4] H.T. Liu, L.N. Gong. Cost-benefit analysis for actualizing demand side management[J]. Electric Power Automation Equipment, 2002, 22(10): 31-33.

[5] S. Rosenstock. Issues in demand side management programs operated by electric utilities in United States[J]. IEEE Transactions on Power Systems, 1993, 8(3): 1560-1572.

[6] W.M. Tang, B.B. Wang, F.B. Liu. Optimal analysis of cost-benefit of demand side management[J]. Power System Technology, 2002, 26(12): 49-52.

[7] J.M. Cheng, F. Nilee, A. Breiplhl, et al. Scheduling direct load control to minimize system operation cost[J]. IEEE Transactions on Power Systems, 1995, 10(4): 1994-2001. 